\title{
Experimental and Numerical Study of Seismic Performance of Precast Prestressed Concrete Frame Internal Connection
}

\author{
Xiandong $\mathrm{LIAO}^{1}$ Xiang $\mathrm{HU}^{2}$ \\ ${ }^{1,2}$ PhD Candidate, Department of Building Engineering, Tongji University, Shanghai, China \\ Corresponding author's e-mail: kz-liaoxiandong@163.com
}

\begin{abstract}
The seismic performance of the internal connection of precast prestressed concrete frame was studied systematically, based on the experiment of full-scale model under low cyclic reversed loading. This study was mainly focused on failure pattern, load-carrying capacity, skeleton curves, and hysteresis curves. Furthermore, a nonlinear finite element analysis using Abaqus was carried out to study the characteristics of the internal connection of precast prestressed concrete frame. Results revealed that the damage was concentrated mainly on beam end owing to flexural action, while steel bars in the columns and stirrups in the core region remained elastic until failure occurred. The calculated value of the load-carrying capacity of the internal connection was similar to the experimental one. Present study can be referenced for the application of precast prestressed concrete frame in high seismic zones.
\end{abstract}

\section{KEYWORDS}

precast prestressed concrete frame internal connection; low cyclic reversed loading; nonlinear finite element analysis; failure pattern; load-carrying capacity

\section{INTRODUCTION}

From the development trend of the construction industry, it is very important for realizing the modernization of the building to improve the degree of prefabrication, and industrialization. Geraldine S. Cheok, Lew H. S. ${ }^{1,2}$ tested precast concrete beam-to-column connections. The test specimens detailed for seismic loads performed satisfactorily in terms of strength, displacement ductility and energy dissipation. A test program conducted by William et al. ${ }^{3}$ studied the characteristics of a hybrid moment-resisting precast connection with precast beams and columns, and the connection could be used inductile moment-resisting frames. Priestley et al. $^{4}$ presented a paper about a test of precast frame joint subassemblages with unbonded tendons. Liu et al. ${ }^{5 \sim 8}$ made many studies about the precast prestressed frame structure, in order to improve the seismic performance of beam-column connections.

Generally, existing studies were mainly focused on the seismic behavior of precast concrete beam-column connections. The experimental investigations and numerical studies on frame structure composed of precast prestressed concrete beams and columns, with a cast-in-place (CIP) layer covering precast prefabricated component, however, were very scarce. In addition, there was an absence of prescriptive seismic code provisions for this kind of precast concrete structures in ACI $318^{9}, \mathrm{EC} 8^{10}$, NZS $310^{11}$, and the Chinese GB $50010^{12}$.

Since 2013, a test of precast prestressed concrete connections and frames composed of precast 
beams and columns, with a CIP layer covering them, was carried out by Xue et al. at Tongji University, China. The objective of this study was to compare experiment and numerical analysis of an internal connection of our team. The construction process of the specimen was expressed as follows: 1) installation of precast beams, slabs, columns, and prestressed tendons; 2) pouring the upper CIP layer; 3) the implementation of pretension and grouting. The beam-column connection could provide the overall connection and continuous frame bearing load, effectively improve the overall performance of the precast prestressed structure.

\section{EXPERIMENTAL PROGRAM}

\section{Design basis}

The precast prestressed concrete specimen tested was a full-scale connection from the bottom story of a prototype building structure in China, which has a large beam cross section of 13.78 x 25.59 in. $(350 \times 650 \mathrm{~mm})$, the column dimensions were $31.50 \times 31.50$ in. $(800 \times 800 \mathrm{~mm})$, and the slabs were $5.91 \mathrm{in}$. $(150 \mathrm{~mm})$. The upper part of all components, including beams and slabs, and the core region, were CIP concrete. The prototype was designed according to a strong column weak beam seismic design philosophy. Prestressed tendons were placed in curve, as showed in Figure 1, and the distance from the top of beam was 5.91 in. $(150 \mathrm{~mm})$.
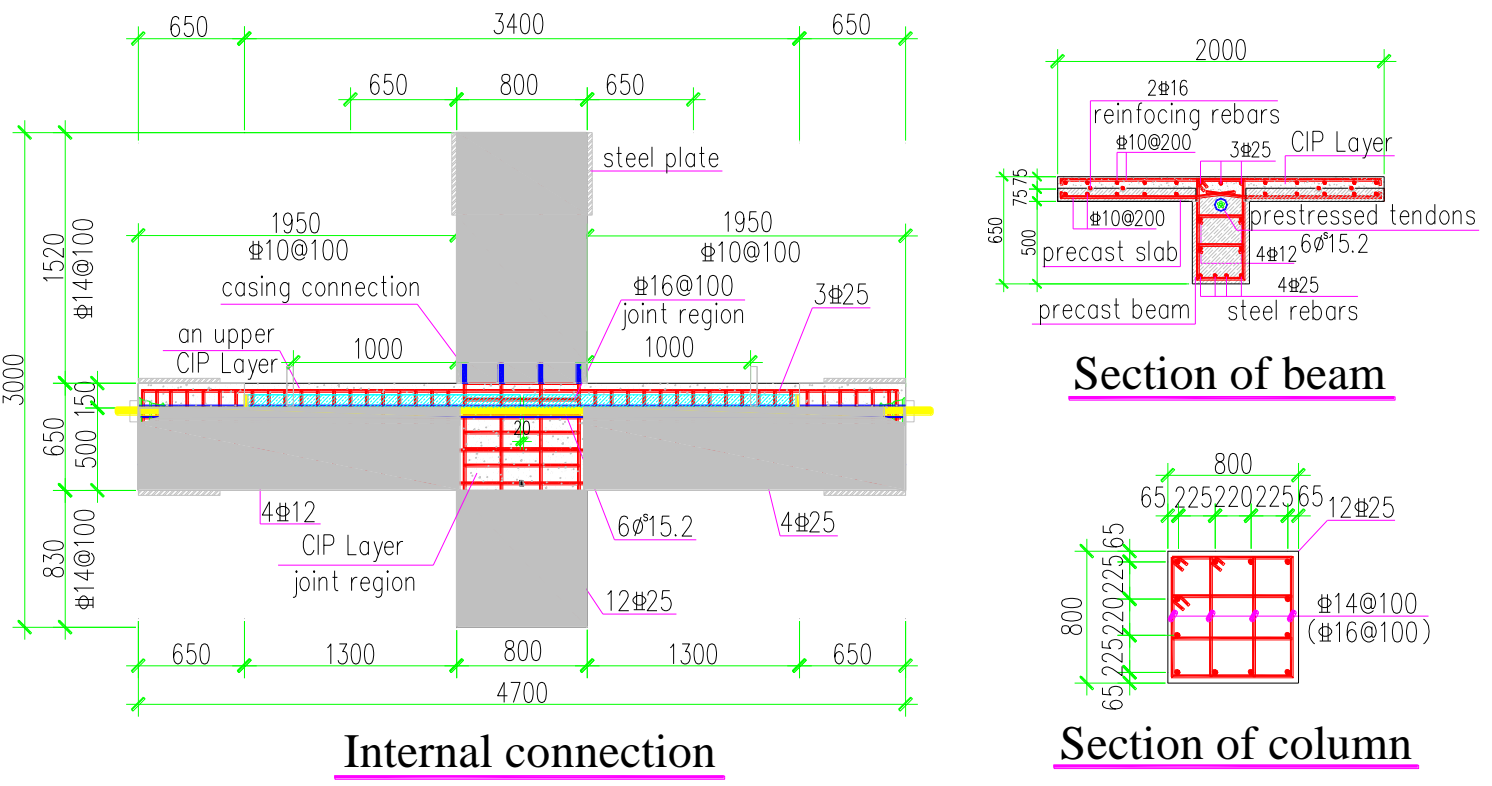

$\underline{\text { Section of beam }}$

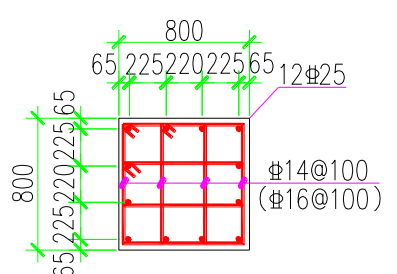

$\underline{\text { Section of column }}$

Figure 1 Specimen geometry and steel details (Note: Dimensions in mm; 1mm=0.0394 in.)

The concrete mixture was designed for a cubic compressive strength of $7.225 \mathrm{ksi}$ (50Mpa, named as C50) for the specimen. Details of the ingredients in concrete are as follows: cement $\left.=24.32 \mathrm{lb} / \mathrm{ft}^{3} 539 \mathrm{~kg} / \mathrm{m}^{3}\right) ; \mathrm{sand}=40.39 \mathrm{lb} / \mathrm{ft}^{3}\left(647 \mathrm{~kg} / \mathrm{m}^{3}\right) ;$ aggregate $=68.791 \mathrm{~b} / \mathrm{ft}^{3}\left(1102 \mathrm{~kg} / \mathrm{m}^{3}\right)$; water $=10.67 \mathrm{lb} / \mathrm{ft}^{3}\left(171 \mathrm{~kg} / \mathrm{m}^{3}\right)$; high-range water-reducing admixture $=0.18 \mathrm{lb} / \mathrm{ft}^{3}\left(2.93 \mathrm{~kg} / \mathrm{m}^{3}\right)$; and fly ash $=5.49 \mathrm{lb} / \mathrm{ft}^{3}\left(88 \mathrm{~kg} / \mathrm{m}^{3}\right)$.

Table 1 Material properties of precast and CIP concrete

\begin{tabular}{c|c|c|c|c|c}
\hline \multicolumn{2}{c|}{ Specimen } & $\begin{array}{c}\text { Cube strength } \\
\mathrm{f}_{\mathrm{cu}}, \mathrm{ksi}(\mathrm{Mpa})\end{array}$ & $\begin{array}{c}\text { Prism strength } \\
\mathrm{f}_{\mathrm{c}}, \mathrm{ksi}(\mathrm{Mpa})\end{array}$ & $\begin{array}{c}\text { Split strength } \\
\mathrm{f}_{\mathrm{t}}, \mathrm{ksi}(\mathrm{Mpa})\end{array}$ & $\begin{array}{c}\text { Elastic modulus } \mathrm{E}_{\mathrm{c}}, \\
\mathrm{ksi}\left(\mathrm{x} 10^{4} \mathrm{Mpa}\right)\end{array}$ \\
\hline \multirow{2}{*}{ PC1 } & CIP & $7.5(51.9)$ & $4.8(33.3)$ & $0.46(3.2)$ & $4887(3.37)$ \\
\cline { 2 - 6 } & precast & $7.6(52.7)$ & $4.9(33.9)$ & $0.49(3.4)$ & $5235(3.61)$ \\
\hline
\end{tabular}

Notes: CIP is cast-in-place concrete; Precast is precast concrete. 
Samples representing all sizes of steel rebars were tested in tension to failure, and Table 2 summarizes the properties of the steel rebars.

Table 2 Material properties of steel rebars

\begin{tabular}{c|c|c|c|c|c}
\hline $\begin{array}{c}\text { Bar } \\
\text { type }\end{array}$ & $\begin{array}{c}\text { Yield strength } \mathrm{f}_{\mathrm{y}}, \\
\mathrm{ksi}(\mathrm{Mpa})\end{array}$ & $\begin{array}{c}\text { Ultimate } \\
\text { strength } \mathrm{f}_{\mathrm{u}}, \\
\mathrm{ksi}(\mathrm{Mpa})\end{array}$ & $\begin{array}{c}\text { Young's } \\
\text { modulus } \mathrm{E}_{\mathrm{s},} \\
\mathrm{ksi}\left(\mathrm{x} 10^{5} \mathrm{Mpa}\right)\end{array}$ & $\begin{array}{c}\text { Yield } \\
\text { strain, } \varepsilon(\mu \mathrm{m})\end{array}$ & $\begin{array}{c}\text { Elongation at } \\
\text { fracture, \% }\end{array}$ \\
\hline$\$ 25$ & $69.6(480)$ & $84.9(586)$ & $27,985(1.93)$ & 3104 & 24.8 \\
\hline$\$ 16$ & $79.7(550)$ & $101.2(698)$ & $27,695(1.91)$ & 2543 & 24.9 \\
\hline$\$ 14$ & $62.6(432)$ & $88.4(610)$ & $26,390(1.82)$ & 2418 & 25.0 \\
\hline$\$ 12$ & $68.1(470)$ & $95.9(662)$ & $27,550(1.90)$ & 2914 & 28.7 \\
\hline$\$ 10$ & $81.3(561)$ & $99.1(684)$ & $26,245(1.81)$ & 2358 & 31.3 \\
\hline $6 \Phi^{\mathrm{s}} 15.2$ & $203.2(1402)$ & $262.3(1810)$ & $27.550(1.90)$ & - & 11.2 \\
\hline
\end{tabular}

Notes: Nominal diameter of bars: $\$ 10=0.39$ in. $(10 \mathrm{~mm}) ; \phi 12=0.47$ in. $(12 \mathrm{~mm}) ; \phi 14=0.55$ in. $(14 \mathrm{~mm})$; $\$ 16=0.63$ in. $(16 \mathrm{~mm}) ; \$ 25=0.98$ in. $(25 \mathrm{~mm})$. Design yield strength was $57.8 \mathrm{ksi}$ (400Mpa) by Abaqus.

\section{Test setup and loading procedure}

The adopted geometry of specimens was determined by the span of beam and column in the prototype structure as well as the loading space and ground anchors in the laboratory. The boundary conditions are presented in Figure 2. In order to simulate internal connection of frame under horizontal loading, the column was supported by a pinned connection at its base, and its top was free, moved by horizontal loading device. The beam end was designed as a roller support. A constant axial load was applied to the column by using a vertical 2,248 kip $(10,000 \mathrm{kN})$ hydraulic actuator, which could automatically trace the column top during loading. The axial compressive ratio $\mu$ was 0.5 , representing the vertical load experienced in the prototype building. Herein, the axial compression ratio $\mu$, is defined as $\mu=N /\left(f_{c}^{*} A\right)$, where $N$ is the axial load, $f_{c}$ is the axial compressive strength of concrete, and $A$ is the area of column cross section (Xue W. C. ${ }^{13,14}$ ). It must be taken to account to keep the beam end freely during adding vertical load to the column, in order to avoid the additional bending moment on the beam end.

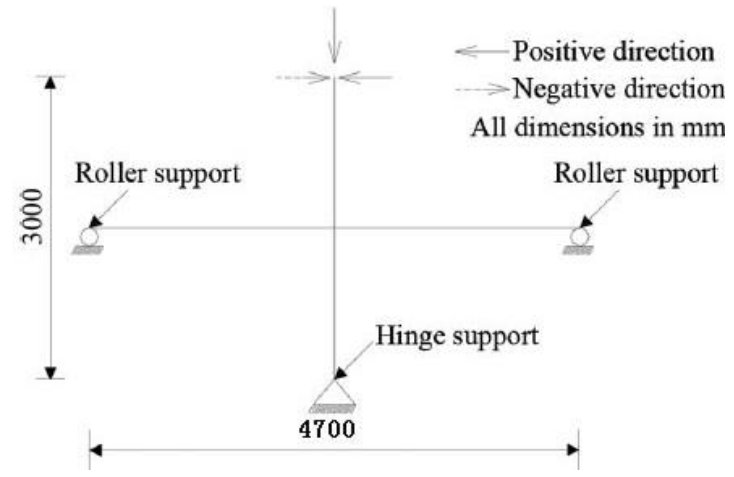

(a) Boundary condition for specimen

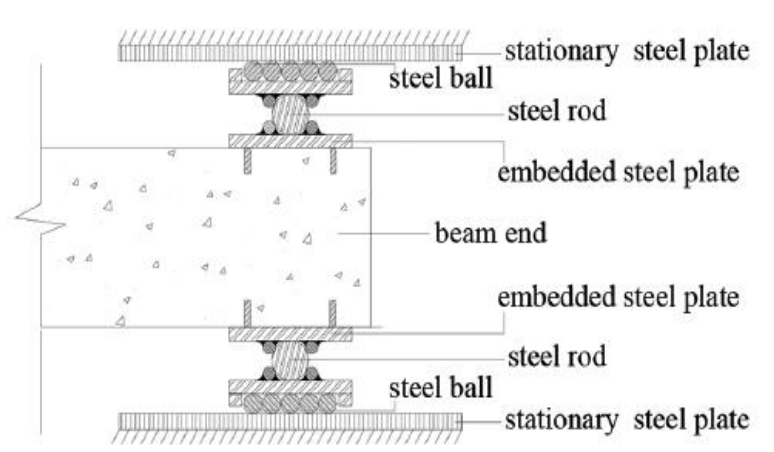

(b) Beam end boundary condition

Figure 2 Boundary conditions

The loading history was divided into two phases. The first phase was a load-controlled phase, and the second one was a displacement-controlled phase consisting of cycles of increasing magnitude $0.5 \%$ story drift, namely 0.59 in. $(15 \mathrm{~mm})$. The first phase was adopted before, and the second one was adopted after the first crack was found on the concrete beam. And three 
cycles were applied at each drift level. Until load-carrying capacity decreased to $85 \%$ of the ultimate capacity, specimen was considered to have been damaged, and test was over. The loading history was shown as Figure 3.

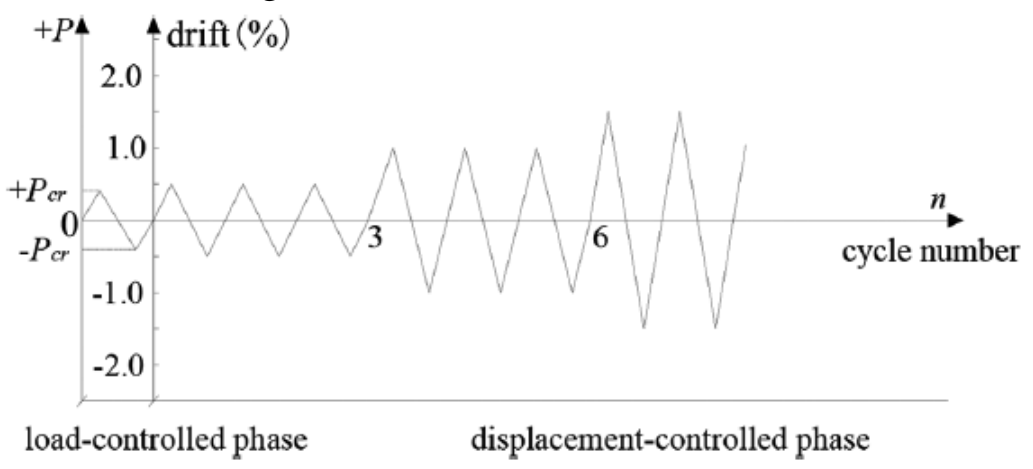

Figure 3 Loading procedure

\section{NONLINEAR FINITE ELEMENT ANALYSIS}

\section{Calculation parameters}

Computational model was set up by Abaqus (computational software) according to the actual size of experimental prototype, including geometry and steel details of beams, slabs, columns, area and location of prestressed tendons, as shown in Figure 1. Calculation was divided into three analysis steps according to the loading process of experiments, the first step was to apply pretension to the concrete structure as external load, by dropping temperature method; the second step was to add a constant axial load to the column; and the third step was to apply story drift to the column (displacement-controlled phase). During applying of the pretension load and constant axial load, the column was supported by a pinned connection, and only the displacement $\delta$ of the axial direction for beams was constrained; the beam end was designed as a roller support, only constrained in $\mathrm{Z}$ direction, other directions released, during applying lateral drift on the top of column.

The constraints between reinforcement and concrete were defined as "Embedded region"; the constraints between loading steel plates and concrete components were defined as "Tie"; "surface-to-surface (standard)", "small sliding", "frictionless", and "softened contact" were adopted to simulate the contact interface (contact pairs) between precast concrete and precast concrete, between precast concrete and CIP concrete; concrete components were meshed with hexahedral elements using C3D8R(an 8-node linear brick, reduced integration, hourglass control type), master surface of contact pairs has an average element size of 0.15 in., while slave surface has an average element size of $0.29 \mathrm{in}$; steel rebars and prestressed tendons were meshed with truss elements using T3D2(a 2-node linear 3-D truss type), which has an average element size of $0.29 \mathrm{in}$.

\section{Constitutive model of plastic damage of concrete}

Reinforcement constitutive model is relatively simple. The mechanical performance of concrete should be mainly due to the complexity of concrete material. It is very important to establish the constitutive model of the concrete (as shown in Fig. 4 and referred to Feng J. et al. ${ }^{15}$ ). It is a bit difficult to accurately describe constitutive model, but it can be understood as the relation of stress with strain (stress-strain curve) under the multi-axial stress. Concrete 
material is mainly in elastic-plastic stage during rising curve, while is in strain-softening stage during decreasing curve. Concrete material exhibited complex plastic properties, when damage accumulation caused cracks to develop deeply. At present, many scholars have made extensive researches in the fields of exploring the mechanical properties and damage model of concrete, obtained a large number of valuable results. Relation of corresponding damage factor and non-elastic strain was shown in Figure 5 (referred to Feng J. et al. ${ }^{15}$ ).
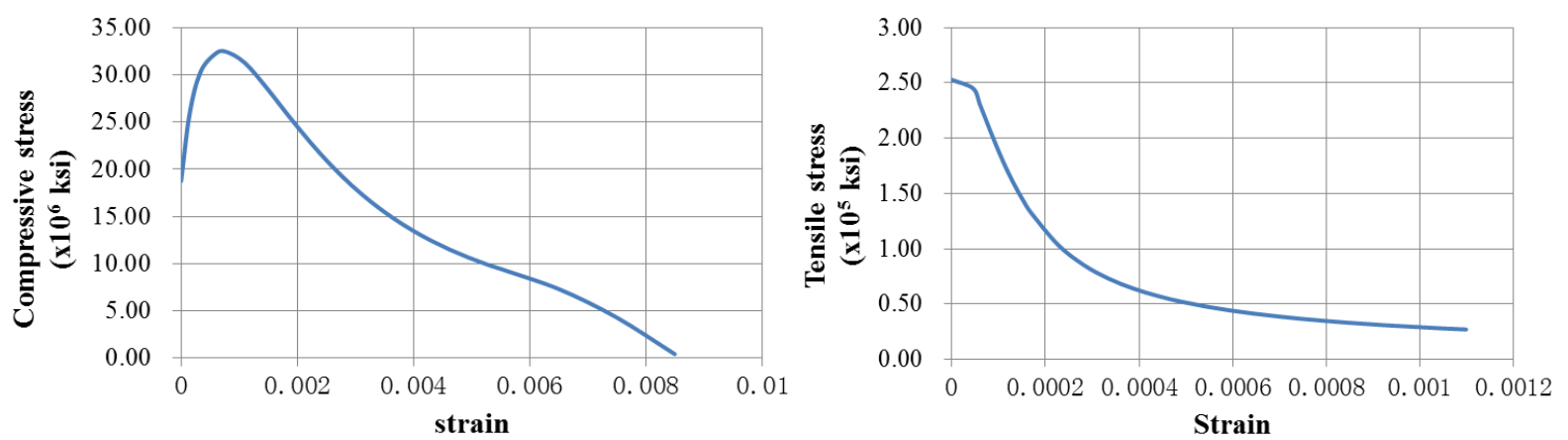

Figure 4 Damage constitutive model of C50 (GB 50010 $\left.{ }^{12}\right)$

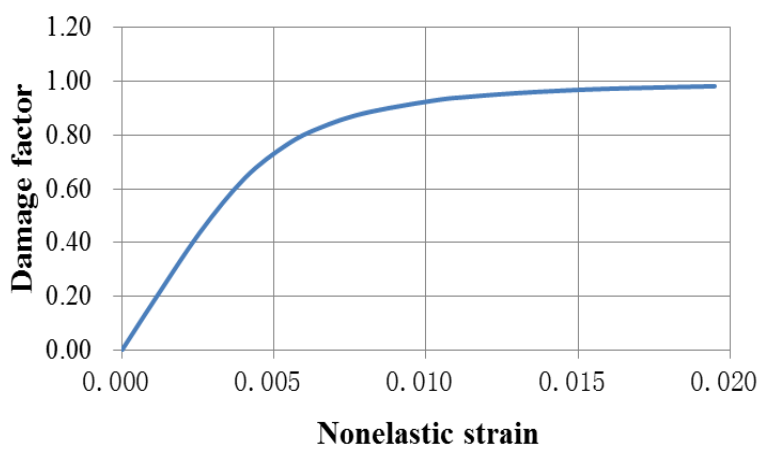

Compression

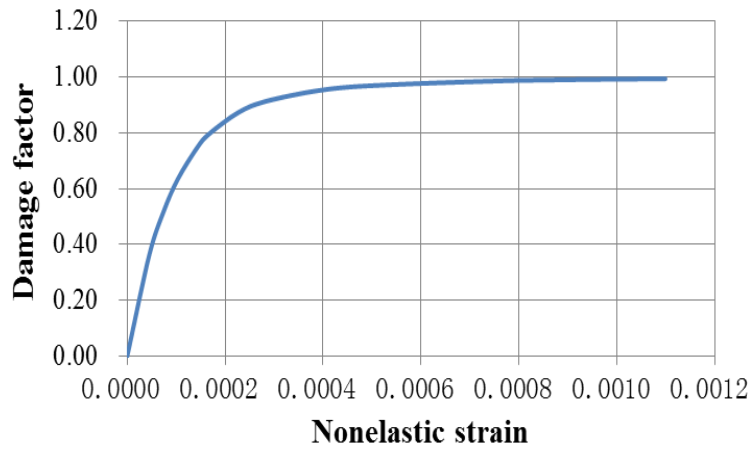

Tensile

Figure 5 Relation of the damage factor and the non-elastic strain

\section{EXPERIMENTAL AND NUMERICAL RESULTS}

This paper developed experimental and numerical study mainly from failure pattern, load-carrying capacity, and skeleton curves.

\section{Failure pattern of the internal connection}

The numerical result was quite similar to the experiment one in the failure pattern of the precast prestressed concrete frame internal connection, which included the formation of a plastic hinge in the beam at the column face. Plastic hinge caused severe main cracking and prominent shear cracks, mainly due to the large depth of the beam. No cracks, however, were observed on the column and in the joint region. It should be noted that there were no horizontal cracks observed between CIP layer and precast concrete until the lateral load reached the peak load, and in the later stage of the test, the horizontal cracks occurred in the interface between the CIP layer and precast concrete in the slabs. Figure 6 showed that longitudinal reinforcements and stirrups were buckling, following concrete crushing, at the bottom of the beam end near the column face, indicating load-carrying capacity losing, test being halted, while there were few hairline cracks on the column and in core region. So the failure pattern of internal connection was typical beam-end damage (as shown in Fig. 7). 


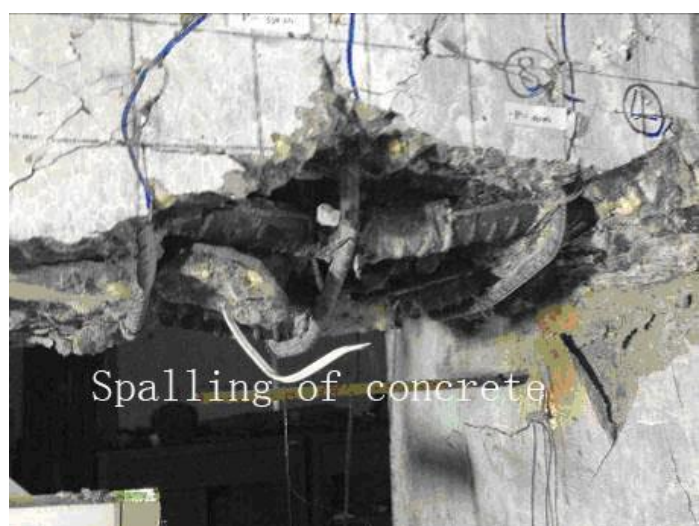

Figure 6 Failure pattern of the beam end

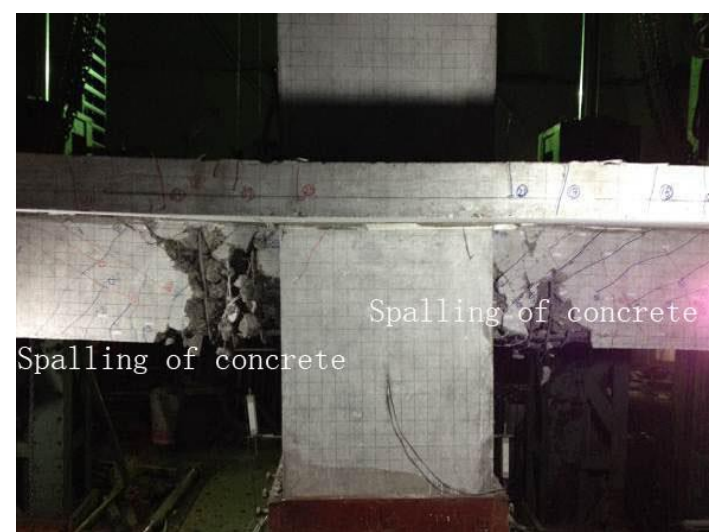

Figure 7 Failure pattern of the specimen

Equivalent plastic stress nephogram, obtained from nonlinear finite element calculation using Abaqus, was showed in Figure 8. The figure reflected directly that plastic damage accumulation of concrete caused the connection to reach the failure strength finally, and reflected indirectly the damage of concrete strength and stiffness. It should be noted that column longitudinal bars and stirrups in joint region maintained always elastic, and prestressed tendons yielded, as showed in Figure 9. The calculation results could well reflect mechanical properties and failure pattern of the connection, which agreed with experimental results very well.
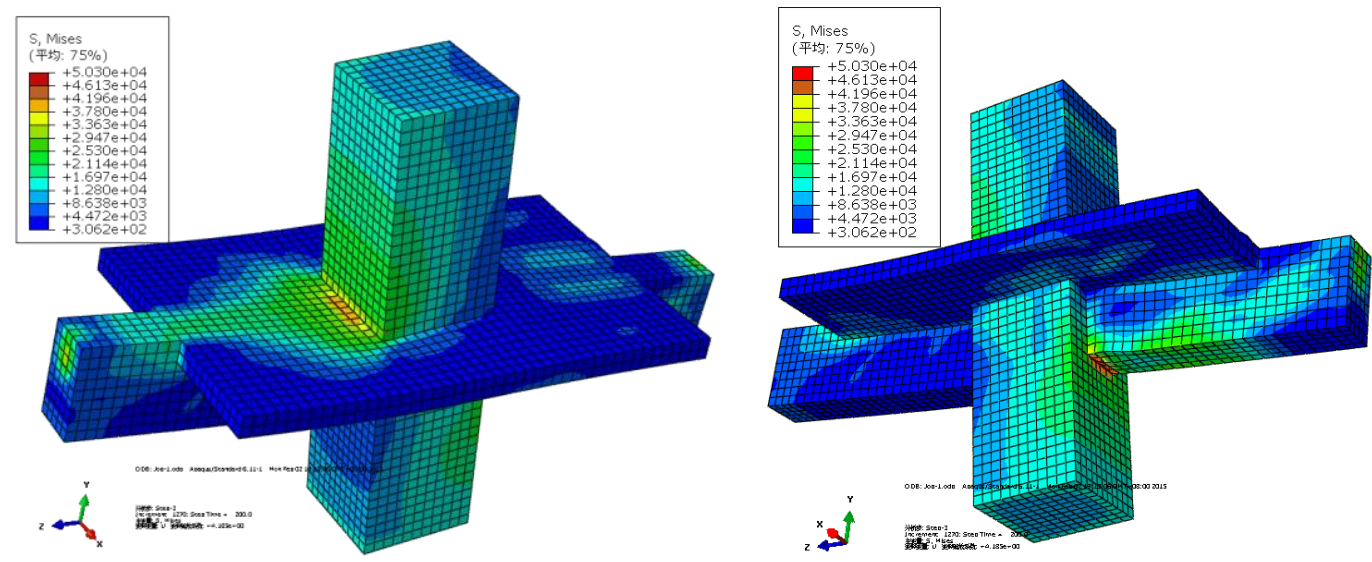

Figure 8 Stress nephogram of the concrete
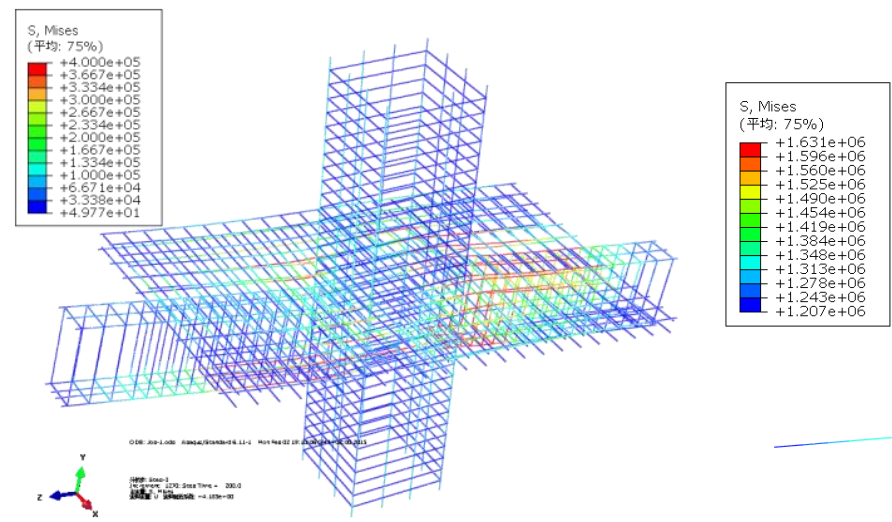

Figure 9 Stress nephogram of steel rebars and prestressed tendons 


\section{Hysteresis curves and skeleton curves}

The lateral load-versus-drift hysteresis curve of specimen was given in Figure 10. The curves, obtained from experiments, exhibited slight pinching and relatively full, as well as some stiffness and strength degradation, during same-drift repeat cycles, which was mainly attributed to bond degradation between concrete and reinforcement, concrete cracking, reinforcement yielding, or their combination.

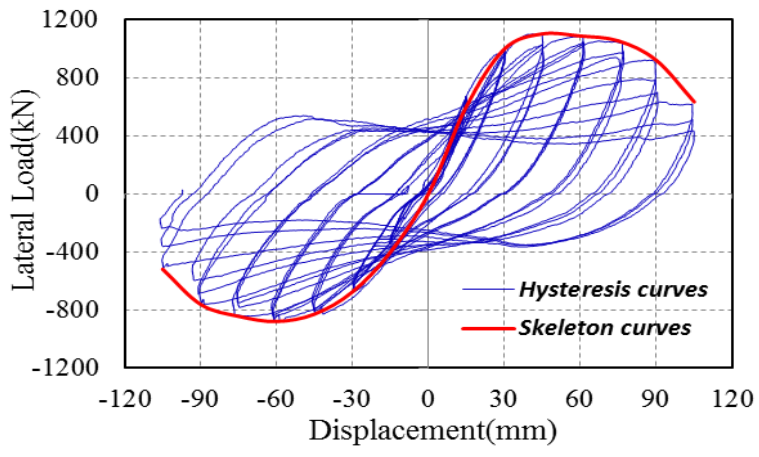

Figure 10 Hysteresis curves

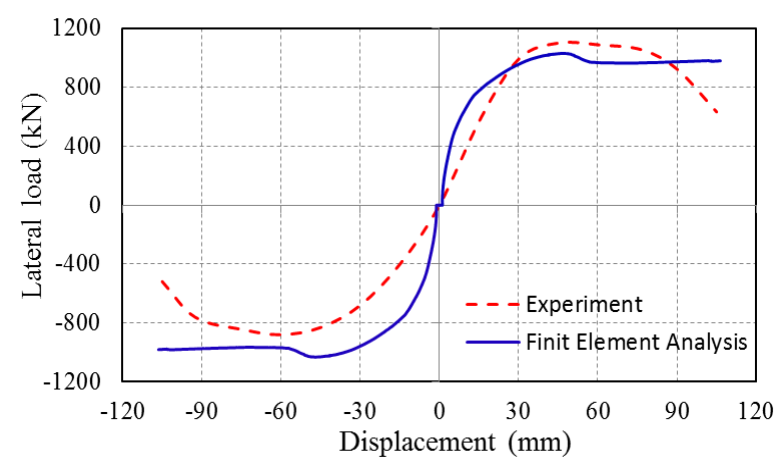

Figure 11 Skeleton curves

The P- $\triangle$ curve obtained from nonlinear finite element analysis and skeleton curve, namely envelopes of hysteresis loops, of experiment were plotted in Fig. 11. It can be seen that positive peak value $1100 \mathrm{kN}$ (247kip) of load-carrying capacity obtained by testing was about $7 \%$ higher than calculated value $1031 \mathrm{kN}$ (227kip), and negative peak value $880 \mathrm{kN}$ (198kip) of the test was about $17 \%$ lower than the calculated value $1031 \mathrm{kN}(227 \mathrm{kip})$, the main reason was: 1) The real boundary condition of the nonlinear finite element calculation model cannot be simulated, and bars slip is simulated by strain softening;

2) Concrete material is defined as isotropic one, the constitutive model is approximately, and the damage model of concrete is a bit different from the entity material;

3) The positive peak value of load-carrying capacity of the internal connection is higher than the negative peak value due to the bolt device, but the positive peak value will be slowly close to the negative one at same drift level, with increasing drift.

In general, the result of nonlinear finite element calculation is very similar to experimental result, which means that the finite element analysis is acceptable.

\section{CONCLUSIONS}

Through the nonlinear finite element analysis and experimental study of the frame internal connection under low cyclic loading, conclusions can be drawn as follows:

1) Abaqus provided "Embed" technology between concrete and reinforcement bars (Embedded region); "surface-to-surface (standard)", "small sliding", "frictionless", and "soft contact" was adopted to simulate the contact surfaces between precast and CIP concrete; pretension was applied by dropping temperature method and so on, these could greatly improve the modeling efficiency of precast prestressed concrete structure;

2) There is a certain deviation between experimental value and calculated value, due to the boundary conditions, material properties, and approximate constitutive model;

3) Calculated results would be quite similar to experimental results in terms of the failure pattern, load-carrying capacity, skeleton curves, based on the reasonable damage model;

4) I believe, nonlinear finite element calculation will be reliable, based on further research on 
materials, especially constitutive damage model of concrete considering anisotropic;

5) Next, research group will develop subsequent and deep study on precast prestressed concrete frames and connections, and contribute to enlarge the application for precast prestressed concrete frame in the high seismic zones.

\section{ACKNOWLEDGMENTS}

The author gratefully acknowledges the financial support provided by the eighth Construction Bureau of Chinese construction.

\section{REFERENCES}

1 Geraldine S. Cheok, Lew H. S. (1991), "Performance of precast concrete beam-to-column connections subject to cyclic loading," PCI Journal, (5-6), 56-67.

2 Geraldine S. Cheok, Lew H. S. (1993), "Model of Precast Concrete Beam-to-Column Connections Subject to Cyclic Loading," PCI Journal, (7-8), 80-92.

3 William C. Stone, Geraldine S. Cheok, John F. Stanton (1995), "Performance of hybrid moment-resisting precast beam-column concrete connections subjected to cyclic loading," ACI Structural Journal, (3-5), 229-249.

4 Priestley, M. J. N., MacRae, G. A. (1996), "Seismic Tests of Precast Beam-Column Joint Subassemblages with Unbonded Tendons," PCI Journal, 41(1), 64-80.

5 Liu B. K., Zhang Y. Z., Jin Z. F. (2005), "Experimental Study on Seismic Behavior of Prestressed Fabricated PC Frame Connections," Journal of building structures, 26(2), 61-65.

6 Dong T. F., Li Z. B., Zhou X. Y. (2006), "Study on Seismic Behavior of Internal Connections of Unbonded Prestressed Assembly Frame," Beijing University of Technology, 32(2), 144-148.

7 Li Z. B., Dong T. F., Zhou X. Y. (2006), "Study on the seismic performance of hybrid connection of the assembly frame," Beijing University of Technology, 32(10), 895-900.

8 Zhong X., Meng S. P. and Pan Q. J. (2007), "Research on Seismic Behavior of Partially Unbonded Precast Prestressed Concrete Frames and Beam-column Subassemblies," Journal of earthquake engineering and engineering vibration, 27(4), 56- 60.

9 ACI Committee 318 (2005), "Building Code Requirements for Structural Concrete (ACI 318-05) and Commentary," American Concrete Institute, Farmington Hills, MI, 430.

10 European Committee for Standardization, EN1998-1 (2004), "EurocodeNo.8 Design of Structures for Earthquake Resistance-Part 1: General Rules, Seismic Actions and Rules for Buildings," Brussels, Belgium, Jan. 232.

11 Standard Association of New Zealand (2006), "The Design of Concrete Structures (NZS3101:2006)," Wellington, New Zealand, 18-1 to 18-8.10.

12 Chinese Standard GB (Guobiao) (2010), "Code for Design of Concrete Structures (GB50010-2010)," Chinese Building Press, Beijing, China, 19-21.

13 Xue W.C.; Zhao B. (2014), "Seismic Behavior of Hybrid Concrete Beam-Column Connections with Composite Beams and Cast-in-Place," ACI Structural Journal, 111(3), 617-627.

14 Xue, W. C., and Yang, X. L. (2010), "Seismic Tests of Precast Concrete, Moment-Resisting Frames and Connections," PCI Journal, 55(2), 102-121.

15 Zhang, Z., Cai, J. G., Feng, J. (2012), "Nonlinear Analysis of the Middle Node of Frame Structure Under Cycle Loading”, Sichuan Building Science, 38(2), 47-51. 